\section{Síndrome de artritis por antitiroideos}

\section{Sr. Director:}

Hemos leído con agrado el artículo titulado "Síndrome de poliartritis por antitiroideos", y queremos hacer algunas consideraciones que estimamos de interés. Todos los fármacos que se emplean por sus efectos beneficiosos, pueden producir efectos adversos que afecten a cualquier órgano o sistema del organismo. Las artralgias y artritis inducidas por drogas han sido ampliamente estudiadas, pudiendo aparecer por agravar o precipitar una enfermedad preexistente, o desencadenarlas en sujetos previamente sanos ${ }^{2}$. Los efectos adversos de los antitiroideos son poco frecuentes. Desde 1945 se han publi-cado menos de 100 casos de manifestaciones sistémicas relacionadas con drogas antitiroideas ${ }^{3}$. Los efectos secundarios han sido descritos con mayor frecuencia con propiltiouracilo que con carbimazol o metimazol ${ }^{4}$.

Los tres fármacos antitiroideos disponibles son tioureas. El carbimazol se metaboliza completamente a metimazol y sólo el metabolito es responsa- ble del efecto farmacológico. Todos los agentes antitiroideos contienen un grupo tioamida por lo que cabe esperar reactividad cruzada; ésta es completa entre carbimazol y metimazol ${ }^{5}$. Por ello, ante un cuadro de reacción adversa a uno de estos fármacos, no está indicado el tratamiento de prueba con el otro. La reactividad cruzada entre propiltiouracilo y carbimazol o metimazol ha sido notificada en ocasiones, aunque se desconoce la incidencia y la relevancia clínica no está bien establecida. Los diferentes estudios estiman la probabilidad de que se repita la misma reacción adversa por sensibilidad cruzada en un 20-50\% de los casos $^{6}$. Por ello, si el cuadro es grave, tampoco emplearemos otra tionamida, requiriendo en este caso tratamiento con ${ }^{131} \mathrm{I}$ o con cirugía. Si el efecto secundario ha sido leve, podremos probar con otra.

\section{F. J. Zufía García, R. Ruiz Giardin, B. López Serrano}

Médicos de Familia. C.S. El Espinillo. Área 11. INSALUD. Madrid

\section{BIBLIOGRAFÍA}

1. Sanz B, Quintana JL, Gonzalez Al. Síndrome de poliartritis por antitiroideos Medifam 2001; 11: 92-6

2. Hart FD. Drug-induced artritis and arthralgia. Drugs 1984; 28: 34754.

3. Mathieu E, Fain O, Sitbon M, Thomas M. Systemic adverse effect of antithyroid drugs. Clin Rheumatol 1999; 18: 66-8.

4. Bartalena L, Bogazzi F, Martino E. Adverse effects of thyroid hormone preparations and antithyroid drugs. Drug Safety 1996; 15(1): 53-63.

5. Smith A, Gledhill RF, Jenkins P. Cross sensitivity to antithyroid drugs. BMJ 1989; 298: 1253.

6. Richards AJ, Bell MJ. Antithyroid Arthritis Syndrome-A case induced by carbimazole. J Rheumatol 1999; 26: 1851.

\section{Anisakiasis, una patología en aumento en España}

Sr. Director:

Anisakiasis es una patología en continuo aumento en España en los últimos años por lo que desde la Atención Primaria debemos conocer y sospechar esta patología y su profilaxis. Sin duda que la internacionalización de ciertas culturas gastronómicas ha influido poderosamente en esta 
situación (ingesta de pescado crudo, ahumado, en salazón, marinados, etc.). A propósito de un caso de anisakiasis alérgica registrado en nuestra consulta, realizamos una revisión de la literatura.

Caso: paciente varón de 56 años sin antecedentes de interés que había presentado dos episodios de urticaria de comienzo por la tarde. En la anamnesis refería la toma de pescado tres horas antes en la comida (merluza y bacalao respectivamente). Remitido al Servicio de Alergología se confirmó la existencia de sensibilización a Anisakis simplex. Tras suspender inicialmente la ingesta de pescados y cefalópodos de la dieta del paciente, no se han vuelto a registrar nuevos cuadros urticariales.

El Anisakis es un parásito de la clase Nematodo y de la familia Anisakidae del que se conocen cuatro especies: simplex, physeteris, tipica y schupakovi. Todas sus especies son habitualmente parásitos del estómago de mamíferos marinos y el ciclo vital del parásito puede incluir uno o más huéspedes intermediarios (crustáceos, peces y cefalópodos). El hombre es un huésped aberrante ya que en él la larva no consigue alcanzar la madurez sexual y la forma de adquirirlas es a través de la ingestión de pescado crudo o insuficientemente cocinado, ahumado, salazón, seco o en vinagre, semiconservas, ceviche y variedades de cocina japonesa como sushi o sashimi ${ }^{1}$. La tasa de parasitación por anisakis del pescado que llega a nuestros mercados es alta (hasta un 40-80\% de las piezas en función de las espe(ies) $)^{2}$.

La parasitación del hombre por la larva viva se denomina anisakiasis o anisakidosis y su patología se diferencia en varias formas clínicas: la anisakiasis luminal, en la que no hay penetración sino adherencia asintomática de la larva al tracto digestivo. En estos casos las larvas mueren en un periodo de semanas y son expulsadas con las heces. La anisakiasis gástrica en la que las larvas mediante la acción de peptidasas penetran hasta la submucosa gástrica produciendo de forma aguda cuadros de dolor epigástrico, náuseas y vómitos ${ }^{3}$. La anisakiasis intestinal en la que las larvas invaden la pared intestinal originando síntomas más diferidos en el tiempo como fiebre, náuseas, vómitos, diarrea y abdominalgias y en ocasiones, verdaderas ileítis, apendicitis y cuadros de obstrucción y pseudobstrucción intestinal ${ }^{4}$. La $a n i$ sakiasis gastroalérgica que origina síntomas alérgicos más severos que los gástricos (desde urticaria y angioedema hasta shock anafiláctico), tras la ingesta de pescado ${ }^{5}$. Parece ser que en la mayoría de los casos es el parásito vivo la fuente antigénica y que necesita fijarse a la submucosa para producir la reacción de hipersensibilidad mediada por $\mathrm{IgE}^{6}$. El mejor tratamiento frente a la anisakiasis es la profilaxis evitando tomar pescados y cefalópodos crudos o insuficientemente cocinados. Estos alimentos deben ser cocinados a $60{ }^{\circ} \mathrm{C}$ y un mínimo de 5 minutos. Así mismo el ahumado industrial debe alcanzar los $60^{\circ} \mathrm{C}$ al menos 10 minutos. La CEE obliga por ley a congelar a $20{ }^{\circ} \mathrm{C}$ durante más de 24 horas todo el pescado que se comercialice para consumirse crudo y esta medida ha disminuido drasticamente la incidencia de anisakiasis en muchas zonas de Europa ${ }^{7}$. En España el problema está en la falta de información de amas/os de casa y restaurantes donde el pescado que se compra y se prepara crudo o poco cocinado no ha seguido esta norma legislativa vigente y por ello cada vez son más numerosos los casos de anisakiasis comunicados en España.

\section{A. Alexandre Ayuso, J. Gutié- rrez Frías*, M. L. Real Gonzá- lez**}

Médico Residente de MFyC. CS Cazoña. Santander. *Médico de Familia. CS Cazoña. Santander. **Médico de Familia. CS La Vega-Zapatón. Torrelavega. Unidad Docente de $\mathrm{MFyC}$ de Cantabria

\section{BIBLIOGRAFÍA}

1. Mira J, García P, Hilario LM, Rodríguez MA. Anisakiasis, una parasitosis emergente en nuestro medio. Rev Clín Esp 1995; 195: 105-8.

2. Pereira JM. Algunos aspectos de la epidemiología y prevención de la anisakiasis. Consejería de Sanidad y Bienestar Social. Junta de Castilla y León. Valladolid; 1992.

3. Rosel L, Blanco JR, Oteo JA. Infestación y alergia por Anisakis. Medicina Integral 1999; 33 (9): 412-5.

4. Domínguez J, Cimarra M, SeviIla MC, Alonso A, Moneo I, Robledo T, et al. Anisakis simplex: una causa de pseudobstrucción intestinal. Rev Esp Enferm Dig 2000; 92 (3): 132-5.

5. Alonso A, Daschner A, MorenoAncillo A. Anaphylaxis with Anisakis simplex in the gastric mucosa. N Engl J Med 1997; 337: 350-1.

6. López MC, Alonso A, MorenoAncillo A, Daschner A, Suárez de Parga J. Anisakiasis gastro-alérgica: Hipersensibilidad inmediata debida a parasitación por Anisakis simplex. Rev Esp Alergol Inmunol Clin 2000; 15: 230-6.

7. ECOD. Directive 93/140/EC. March 9, 1993; 156: 42. 
